\title{
The contribution of fire research to fire management: a critical review of a long-term experiment in the Kruger National Park, South Africa
}

\author{
Brian W. van Wilgen ${ }^{\mathrm{A}, \mathrm{C}}$, Navashni Govender ${ }^{\mathrm{B}}$ and Harry C. Biggs ${ }^{\mathrm{B}}$ \\ ${ }^{A}$ Centre for Invasion Biology, CSIR Natural Resources and the Environment, PO Box 320, \\ Stellenbosch 7599, South Africa. \\ ${ }^{B}$ Scientific Services, Kruger National Park, Private Bag X402, Skukuza 1350, South Africa. \\ ${ }^{\mathrm{C}}$ Corresponding author. Email: bvwilgen@csir.co.za
}

\begin{abstract}
The present paper reviews a long-term fire experiment in the Kruger National Park, South Africa, established in 1954 to support fire management. The paper's goals are: (1) to assess learning, with a focus on relevance for fire management; (2) to examine how findings influenced changes in fire management; and (3) to reflect on the experiment's future. Results show that fire treatments affected vegetation structure and biomass more than species composition. Effects on vegetation were most marked in extreme treatments (annual burning, burning in the summer wet season, or long periods of fire exclusion), and were greater in areas of higher rainfall. Faunal communities and soil physiology were largely unaffected by fire. Since the inception of the experiment, paradigms in savanna ecology have changed to encompass heterogeneity and variability. The design of the experiment, reflecting the understanding of the 1950s, does not cater for variability, and as a result, the experiment had little direct influence on changes in management policy. Notwithstanding this, managers accept that basic research influences the understanding of fundamental ecosystem function, and they recognise that it promotes appropriate adaptive management by contributing to predictive understanding. This has been a major reason for maintaining the experiment for over 50 years.
\end{abstract}

Additional keywords: elephants, fire frequency, fire regimes, fire season, savanna.

\section{Introduction}

Fire is an important process in savanna ecosystems, where it acts both as a generalist herbivore (see Bond and Keeley 2005), and as a facilitator of the coexistence of trees and grasses (Higgins et al. 2000). Fire has long been used in the management of savannas, and this management has been informed and adapted by the findings of ongoing research. In southern African conservation (and rangeland) areas, fire was initially viewed as an evil to be avoided, and later as an agent that would maintain these areas in a pristine 'state', through its application in fixed seasons and at fixed return intervals. As savanna ecology adopted a new paradigm of non-equilibrium theory, management sought to implement more flexible approaches to the use of fire in southern African conservation areas (Mentis and Bailey 1990; van Wilgen et al. 1998; Bond and Archibald 2003). These developments reflected those in other parts of the world, where there has been a growing realisation that the homogeneous and regular application of fire reduces the overall productivity of rangelands, and that this has critical impacts on biodiversity and wildlife habitats (Fuhlendorf and Engle 2001, 2004). These changes in thinking have taken place over more than half a century, during which time they have gradually become accepted, and implemented in many areas.

The development of an understanding of the effects of fire is often supported by research based on the experimental application of selected fire regimes on fixed areas (see, for example,
Knapp et al. 1998; Andersen et al. 2003). Such experiments reflect the thinking of the time of their initiation, but they are usually long-term in nature, with treatments often repeatedly applied for many decades. Interest in long-term ecological research has grown internationally over the last quarter century, as evidenced by the International Long-term Ecological Research initiative (www.ilternet.edu/, accessed 25 September 2007). Although the case for such research is well articulated and solid, carrying out such long-term research is beset with challenges. For example, experimental objectives often change over time, and almost all experiments are periodically threatened with closure. In many cases such experiments, once initiated, gradually become forgotten because they do not produce an ongoing stream of products, or because priorities change. The value of and continued support for such experiments is therefore the subject of ongoing debate and contention.

In the present paper, we provide a critical review of one such experiment - a long-term, plot-based, replicated fire experiment in the Kruger National Park in South Africa. The experiment was established in 1954 to provide a basis for scientific fire management of the park. Our review has three goals: (1) to assess what we have learnt from this experiment, with a special focus on the relevance of findings for fire management; (2) to examine whether and how these findings influenced changes in fire management policies in the park, against a backdrop of changing ecological paradigms; and (3) to reflect on the value and 
future of the experiment. As our focus is on the relevance of the experiment to the ongoing improvement of fire management in the park, we also briefly review the history of fire management in the park.

\section{The Kruger National Park}

The Kruger National Park was proclaimed in 1926, and covers 1948528 ha. It has a mean annual rainfall that varies from $\sim 350 \mathrm{~mm}$ in the north to $\sim 750 \mathrm{~mm}$ in the south. The rainfall regime is characterised by extended wet and dry periods, in which the rainfall is either higher than the long-term mean, or lower than the mean, for between 6 and 12 consecutive years. These extended wet and dry periods have marked effects on the occurrence of fires, mainly through their influence on grass fuel loads (van Wilgen et al. 2004). The vegetation of the park is a well-wooded savanna, dominated by trees in the genera Acacia, Combretum, Sclerocarya, and Colophospermum. The fire regime in the park is characterised by fires concentrated in the late dry season. Mean fire-return intervals between 1941 and 1996 ranged between 2.7 and 7.1 years in different landscapes of the park, with an overall mean of 4.5 years (van Wilgen et al. 2000).

\section{Experimental fire research in the Kruger National Park}

Fire research began formally in the Kruger National Park with the establishment in 1954 of an experiment to test the effects of fire on the vegetation (Van der Schijff 1958). The aim of the experiment was to study the effects of fire on the vegetation of the Kruger National Park under the grazing pressure of indigenous herbivores. This was in contrast to the fire research that had been undertaken by the government's Department of Agriculture at the time, which considered primarily domestic livestock (Van der Schijff 1958). The experiment consisted of the application of fires at varying return intervals and seasons, and protection from fire, on a series of 7 ha plots in four of the major vegetation types (Sourveld, Combretum, KnobthornMarula and Mopane vegetation types) of the Kruger National Park (Fig. 1, Table 1). The experiment was open to grazing and browsing by a diverse suite of herbivores, and this may have mediated or masked the effects of fire. The treatments originally included annual winter fires in August and biennial and triennial fires in August, October, December, February and April. In 1976, further treatments to examine the effects of fires every 4 and 6 years in October were added to the experiment (Table 2). Although considerable effort was made to adhere to the fire frequency and season treatments over the $\sim 50+$ year duration of the experiment, not every plot was burnt according to schedule mainly owing to weather, lack of standing biomass, or unintentional burning. Adherence to the planned treatments tended to deviate more in the relatively arid landscapes (Fig. 2). Full details of the experimental design and application of treatments are available elsewhere (Biggs et al. 2003).

In contrast to the considerable effort to adhere to the scheduled experimental treatments, there were relatively few attempts at the analysis and interpretation of data arising from the experiment during the first four decades of the experiment's existence. In order to assess scientific output, we compiled a list of all research products (published papers, reports, theses and datasets) emanating from the fire experiment. We used an earlier report

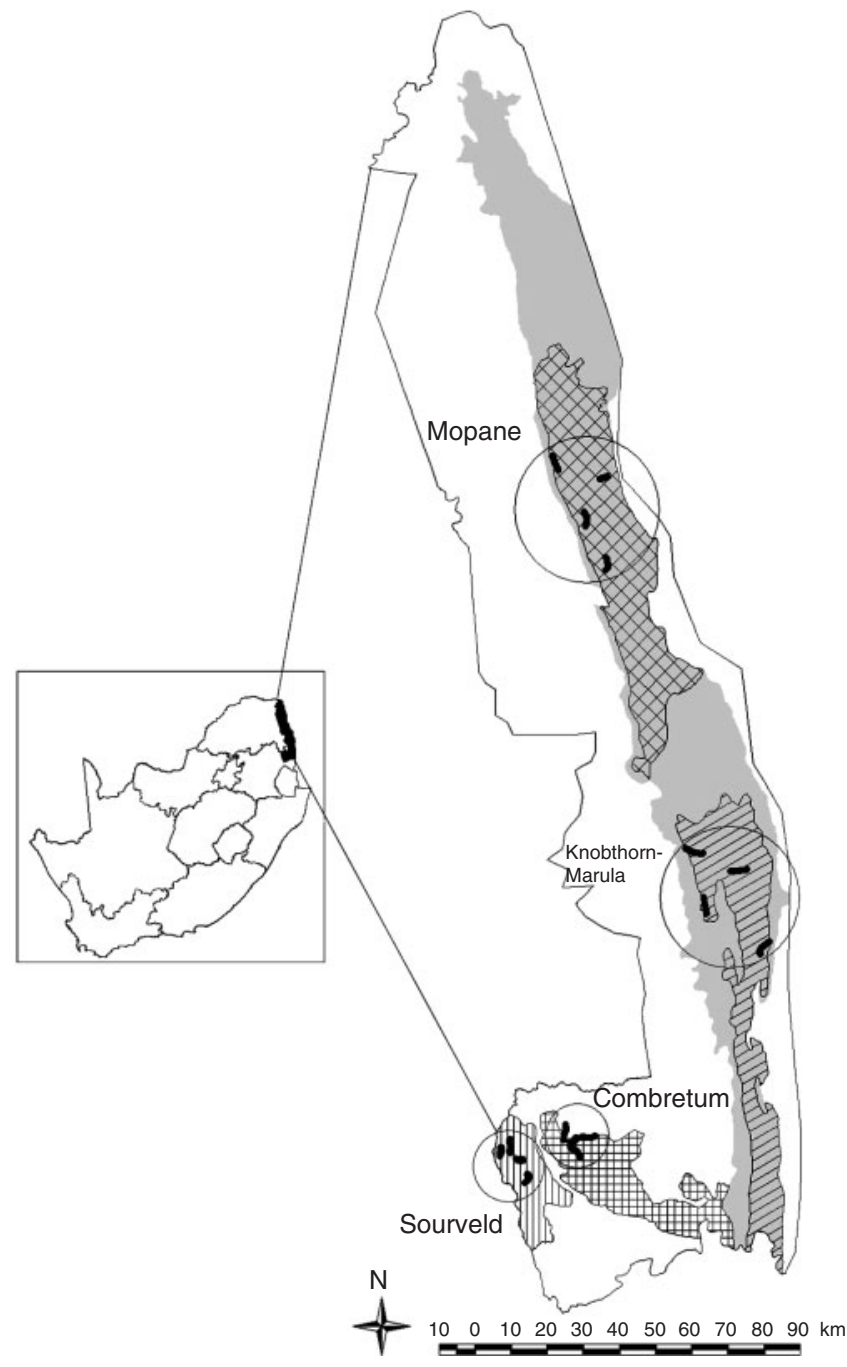

Fig. 1. Location of replicates of a fire experiment in four major vegetation types (hatched and striped areas, see Table 1) of the Kruger National Park, South Africa. The experiment was spread across a north-south precipitation gradient and among two dominant geological types (unshaded=granite, grey shading $=$ basalt).

Table 1. Salient features of four vegetation types in which the Kruger National Park's fire experiment was replicated

\begin{tabular}{lllc}
\hline Vegetation type & Dominant tree species & Geology & $\begin{array}{c}\text { Mean annual } \\
\text { rainfall (mm) }\end{array}$ \\
\hline Sourveld & $\begin{array}{c}\text { Terminalia sericea, } \\
\text { Dichrostachys cinerea } \\
\text { Combretum }\end{array}$ & Granite & 705 \\
Knobthorn-Marula & $\begin{array}{c}\text { C. zeyheri } \\
\text { Acacia nigrescens, } \\
\text { Sclerocarya birrea } \\
\text { Mopane }\end{array}$ & Granite & 572 \\
\hline
\end{tabular}

(Trollope et al. 1998) as a starting point for the list, but eliminated many products that clearly had little or no connection with the fire experiment, and added new products produced after 1998. In total, 67 products have been produced since the 
Table 2. Burning treatments applied in the fire experiment in four major vegetation types in the Kruger National Park

The symbol ' $X$ ' indicates treatments initiated between 1956 and 1958 , and ' $\mathrm{Y}$ ' in 1976 (fires at 4- and 6-year intervals were only applied in the Knobthorn-Marula and Mopane vegetation types). A dash (-) indicates that the combination of treatment and frequency did not exist

\begin{tabular}{lccccccc}
\hline Fire treatment & \multicolumn{7}{c}{ Planned fire frequency (years) } \\
& 1 & 2 & 3 & 4 & 6 & $>50$ (no fire) \\
\hline February (late summer) & - & $\mathrm{X}$ & $\mathrm{X}$ & - & - & - \\
April (autumn) & - & $\mathrm{X}$ & $\mathrm{X}$ & - & - & - \\
August (late winter) & $\mathrm{X}$ & $\mathrm{X}$ & $\mathrm{X}$ & - & - & - \\
October (after first spring rains) & - & $\mathrm{X}$ & $\mathrm{X}$ & $\mathrm{Y}$ & $\mathrm{Y}$ & - \\
December (mid-summer) & - & $\mathrm{X}$ & $\mathrm{X}$ & - & - & - \\
Protection from fire (control) & - & - & - & - & - & $\mathrm{X}$ \\
\hline
\end{tabular}

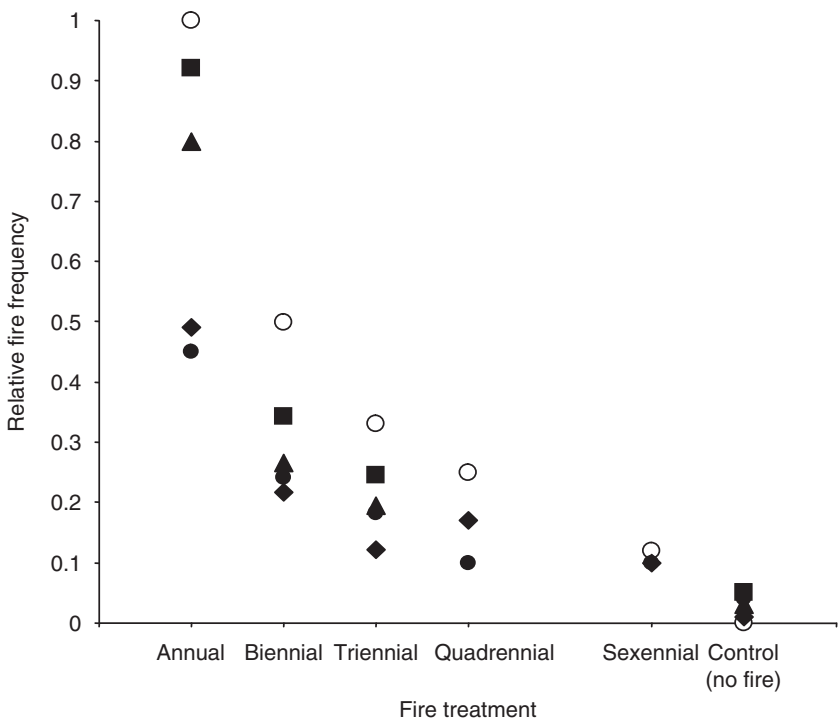

Fig. 2. The relative fire frequency (calculated as $x / y$, where $x=$ the number of fires applied and $y=$ the years of existence of the treatment) achieved for different fire treatments (various frequencies or protection from fire) on experimental burning plots in the Kruger National Park in Sourveld (ם) Combretum ( $\boldsymbol{\Delta})$, Knobthorn-Marula $(\diamond)$ and Mopane $(\bullet)$ vegetation types. Open circles $(\bigcirc)$ indicate the intended level of treatment

inception of the experiment; most of these have been produced in the past decade (Fig. 3).

\section{Focus of research during the fire experiment}

The experiment commenced in 1954 with baseline surveys of the condition of the vegetation, following which routine weather observations were instituted in 1958, along with the application of planned treatments (Fig. 4). Occasional efforts were subsequently made to improve on field survey techniques (Davidson et al. 1961; Trollope et al. 1989); later, the experimental sites were used to ground-truth remotely sensed satellite data (Hetherington 1997; Landmann 2003). At the end of the 1960s, a technician (Mr A. L. F. Potgieter) was appointed with the primary responsibility of overseeing the ongoing implementation of the fire experiment. In 1971, he completed a comprehensive resurvey of the woody (but not herbaceous) vegetation on all of

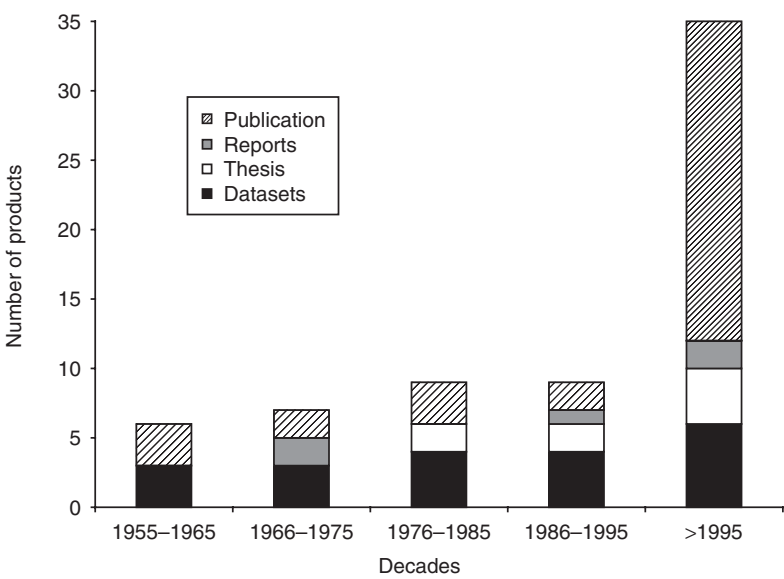

Fig. 3. The number of research products arising from the Kruger National Park's fire experiment per decade. Shading shows the type of product.

the experimental plots. Between 1960 and 1979, partial analyses of the response of the vegetation to burning treatments were published (Anon. 1960; van Wyk 1971; Gertenbach and Potgieter 1979; W. P. D. Gertenbach and A. L. F. Potgieter, National Parks Board of South Africa, unpubl. data)

By the mid-1970s, concern was being expressed that attempts at rigid adherence to fixed-interval burning may have undesirable effects (based on a growing realisation that a degree of variability would be required in 'natural' ecosystems), and the management policy in the park was changed to allow for more flexible, and longer, intervals between fires (Biggs and Potgieter 1999; van Wilgen et al. 2003). In 1976, the fire experiment was modified to allow for fire treatments at longer intervals (4 and 6 years) in spring, with the additional objectives of establishing the effects of these longer intervals between fires (Biggs et al. 2003). The experiment's objectives and design have remained unaltered since then. Between 1977 and 1992, the plots were used, opportunistically it seems, to study the impacts of fire treatments on small mammals (Kern 1977, 1981) and on soil physiological features of the ecosystems (Webber 1979; Jones et al. 1990; Otter 1992).

Serious interest in the experiment was revived in 1980 when Prof. W. S. W. Trollope, a fire ecologist from the University of Fort Hare, spent a period of sabbatical leave in the park. During this year, Prof. Trollope developed and instituted a system for the routine recording of fire behaviour at all experimental burns, a step that introduced new thinking into the experiment, particularly with regard to the impacts of fire intensity on tree mortality (Trollope and Potgieter 1985; Trollope et al. 1995, 1996). Between 1992 and 1996, the fire experiment (again opportunistically) became a vital component of a large, international field experiment, aimed at establishing the role of savanna fires in the dynamics of atmospheric chemistry (Lindesay et al. 1996). This experiment, dubbed 'SAFARI-92' (an acronym for Southern African Fire-Atmosphere Research Initiative), made extensive use of the Kruger National Park's fire experiment to gather data on gaseous emissions (Andreae et al. 1996; Lacaux et al. 1996; Levine et al. 1996; Parsons et al. 1996; Shea et al. 1996; Ward et al. 1996). This highlighted the value of the experiment as a template for testing new ideas over and above those 


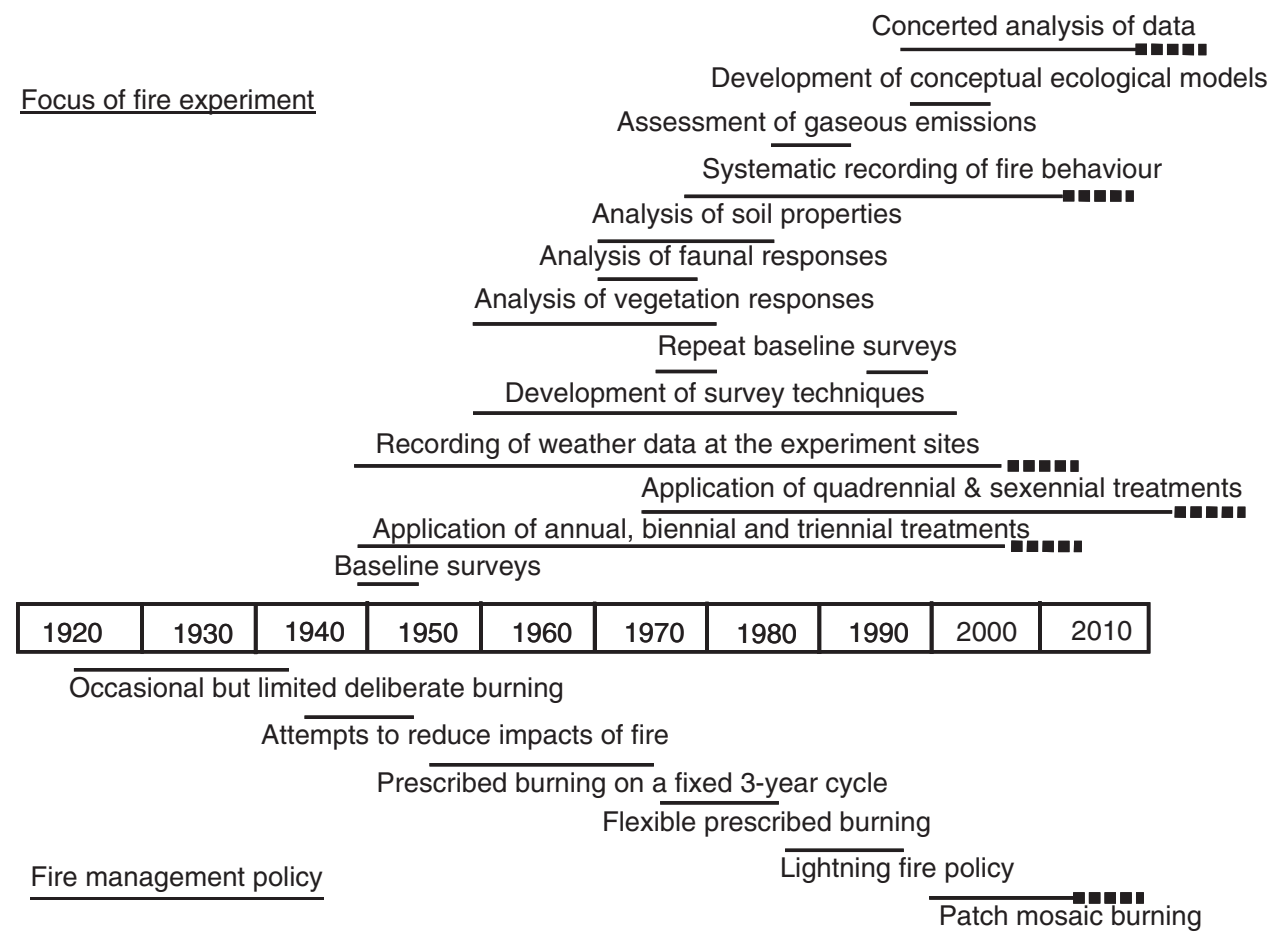

Fig. 4. Activities that formed the focus of the fire experiment in the Kruger National Park over the past century, and corresponding policies adopted for guiding fire management.

envisaged at the experiment's inception. With advances in computer technology at the start of the 21 st century, data from the experimental plots were used in the development of more ecosystem simulation models, to explore the effects of fire on ecosystem dynamics (Higgins et al. 2000; Van Langevelde et al. 2003).

During the 1990s, criticism was levelled at the park's management for the lack of analysis and evaluation of its research efforts, and this (coupled with fresh capacity and enthusiasm for analysis) led to a decision to conduct a program of analysis of historic datasets (Freitag 1998). Students and visiting scientists were encouraged to assist in this process, and the wealth of data and opportunity led to several assessments of the impacts of fire on the experimental plots.

\section{Ecological understanding gained and its relevance to management}

It is not possible to do justice, in a paper such as this, to the volume of information that has emanated from the fire experiment over the past decade. Our purpose is rather to distil the essence of the findings in such a way that the broad implications for fire management can be identified (Table 3). These findings and implications are discussed below with reference to individual ecosystem components.

\section{Effects on woody plants}

Higgins et al. (2007) concluded that fire frequency, fire season, and total fire exclusion did not influence the size of tree populations. Counter to what was expected, there was no decrease in tree density with increasing fire frequency, and this resilience was attributed to the ability of all woody species to resprout from the base after fire. Repeated fires kept individuals small, but they rarely were killed by fire. However, fire had a marked effect on the size, structure and biomass of tree populations. The fire exclusion plots are dominated by larger trees, whereas plots treated by fire had many stunted individuals (Fig. 5). The experiment also showed that different fire regimes had little effect on the species richness of woody plants (Enslin et al. 2000; Shackleton and Scholes 2000; Jacobs and Biggs 2001; O'Regan 2005). In some cases, tree height was reduced slightly in dryseason burns, compared with early wet-season burns (Kennedy and Potgieter 2003). The effects of fire exclusion on woody plants were also more marked in areas of higher rainfall. For example, the increase in biomass following protection from fire over the duration of the experiment ( 6 tonnes ha ${ }^{-1}$ ) at the Sourveld's experimental plots (mean annual rainfall $737 \mathrm{~mm}$ ) was two to six times greater than that at plots in other landscapes experiencing between 496 and $550 \mathrm{~mm}$ of rainfall annually (Higgins et al. 2007).

The quantification of fire intensity at experimental fires allowed for the assessment of this aspect of the fire regime on woody plants. The degree to which the aerial parts of woody plants are scorched, forcing them to resprout from the base (topkill), was found to increase with increasing fire intensity, and to decrease with increasing plant height (Trollope et al. 1995). Fire season had a significant effect on fire intensity (Govender et al. 2006). Mean fire intensities were lowest in summer fires $\left(1225 \mathrm{~kW} \mathrm{~m}^{-1}\right)$, increased in autumn fires $\left(1724 \mathrm{~kW} \mathrm{~m}^{-1}\right)$, and were highest in winter fires $\left(2314 \mathrm{~kW} \mathrm{~m}^{-1}\right)$; this was associated with a three-fold difference between the mean moisture content of grass fuels in winter (28\%) and summer (88\%). Mean fire 
Table 3. The effects of fire on a range of ecosystem features, as determined on experimental burning plots in the Kruger National Park, and the associated implications for fire management in the park

\begin{tabular}{|c|c|c|}
\hline Ecosystem feature examined & Effect of fire & Implications for management \\
\hline $\begin{array}{l}\text { Woody plant composition } \\
\text { and structure }\end{array}$ & $\begin{array}{l}\text { Tree and shrub density are unresponsive to fire regimes } \\
\text { or fire exclusion; tree size is reduced as fire frequency } \\
\text { increases. Species richness and composition are } \\
\text { little affected by different fire treatments and fire } \\
\text { exclusion. Exclusion of fire promotes dominance } \\
\text { by large trees. }\end{array}$ & $\begin{array}{l}\text { Fire is not critical for the maintenance of woody plant } \\
\text { biodiversity, but does affect structure. Managers wish } \\
\text { to reverse declines in the numbers of large trees, which } \\
\text { is driven by interactions between fire and elephant browsing. } \\
\text { However, given the complexity of ecosystems, manipulating } \\
\text { fire frequency or reducing elephant numbers alone to address } \\
\text { this issue may lead to unexpected results. }\end{array}$ \\
\hline
\end{tabular}

Woody plant mortality Lethal scorching of the aerial parts of woody plants, in fires forcing them to resprout from the base, increases with increasing fire intensity, and decreases with plant height.

Herbaceous plant composition

Community composition changes little with fires in the dormant season, but more so with fire in the wet growing season, and with fire exclusion. Impacts are most marked in wetter areas.

Small mammals

There are noticeable effects of fire on small mammal mammal communities, with unburnt sites supporting the most species and the highest densities.

Birds

Species richness and composition do not vary in response to fire intensity.

Ants

There is no significant effect of burning on ant species richness and abundance between fire treatments, but significant differences in ant assemblage composition exist between burnt and unburnt plots.

Mycorrhizae

Mycorrhizal colonisation increases, and root branching and fine root development decreases with decreasing fire frequency, allowing for optimal acquisition of resources under different fire frequencies.

Soil structure and nutrients

Nitrogen losses during fires are replenished regardless of the fire treatment, although the mechanisms for this are not understood. Frequent (annual) burning increases soil crusting.

Emissions

Carbon and nitrogen emissions increase with biomass and post-fire age. Post-fire biogenic emissions of nitric oxide increase after fire.

Fire behaviour
Mean fire intensities vary with fuel moisture but not post-fire age; seasonal fuel moisture effects thus override those of fuel load. Fire intensity can be predicted from relationships between rainfall, fuel load, and fire season.
Managers can retard or increase the rate at which trees are recruited into the larger, fire-resistant classes by selecting appropriate fire intensity levels (see below).

The manipulation of fire regimes is not critical for the maintenance of herbaceous plant species diversity. Extensive fire exclusion, or wet season fires, which would affect composition, will not be possible in reality.

Protection from fire seems the best option for small diversity, but is not practically achievable. Some species may have to rely on fire refugia for survival.

Bird communities are likely to be maintained within a wide range of fire regimes.

Fire is unlikely to affect the maintenance of ant diversity. The conservation of ant species associated with unburnt areas should be achieved in fire refugia.

Grasses are able to cope with a range of fire frequencies, and their conservation will not depend on the maintenance of a narrow range of fire regimes.

There is no evidence, yet, that infrequent burning (every 2-6 years) may lead to severe nutrient losses and soil crusting. Frequent fires that cause crusting are unlikely on a large scale.

This work alerted managers to problems, of which they were previously aware, relating to atmospheric pollution and nutrient cycling.

Managers can manipulate fire intensity (and thus tree mortality) by choosing the season of fire. Estimated fire intensities from rainfall, fuel load, and fire season can enhance fire records, and the later interpretation of biotic responses to fire. intensities showed no significant differences between annual burns and burns at 2-, 3- and 4-year intervals, despite lower fuel loads in annual burns, suggesting that seasonal fuel moisture effects overrode those of fuel load. The understanding gained as a result of this work will allow managers to potentially manipulate fire intensity (and thus tree stem mortality) by choosing the season of fire.

In general, these findings suggest that trees and shrubs will persist under a wide range of fire regimes, and that manipulation of fire is not critical for the maintenance of woody plant biodiversity. However, managers are concerned that there has been a decline in the number of large trees in the park (Eckhardt et al. 2000), and that this decline is driven by the interactions between fire and browsing by elephants (van Wilgen et al. 2003). Although total fire exclusion will promote the retention of large trees, it is not a practically achievable or otherwise desirable option. Currently, there is a vigorous debate around the management of elephant populations (Owen-Smith et al. 2006), as managing the size of elephant populations may offer the only practical solution to the problem of declines in the numbers of large trees. Whereas managers can possibly increase the rate at which trees are recruited into the larger, fire-resistant classes by selecting for conditions of lower fire intensity and topkill, it is not known whether manipulating fire alone would solve the 


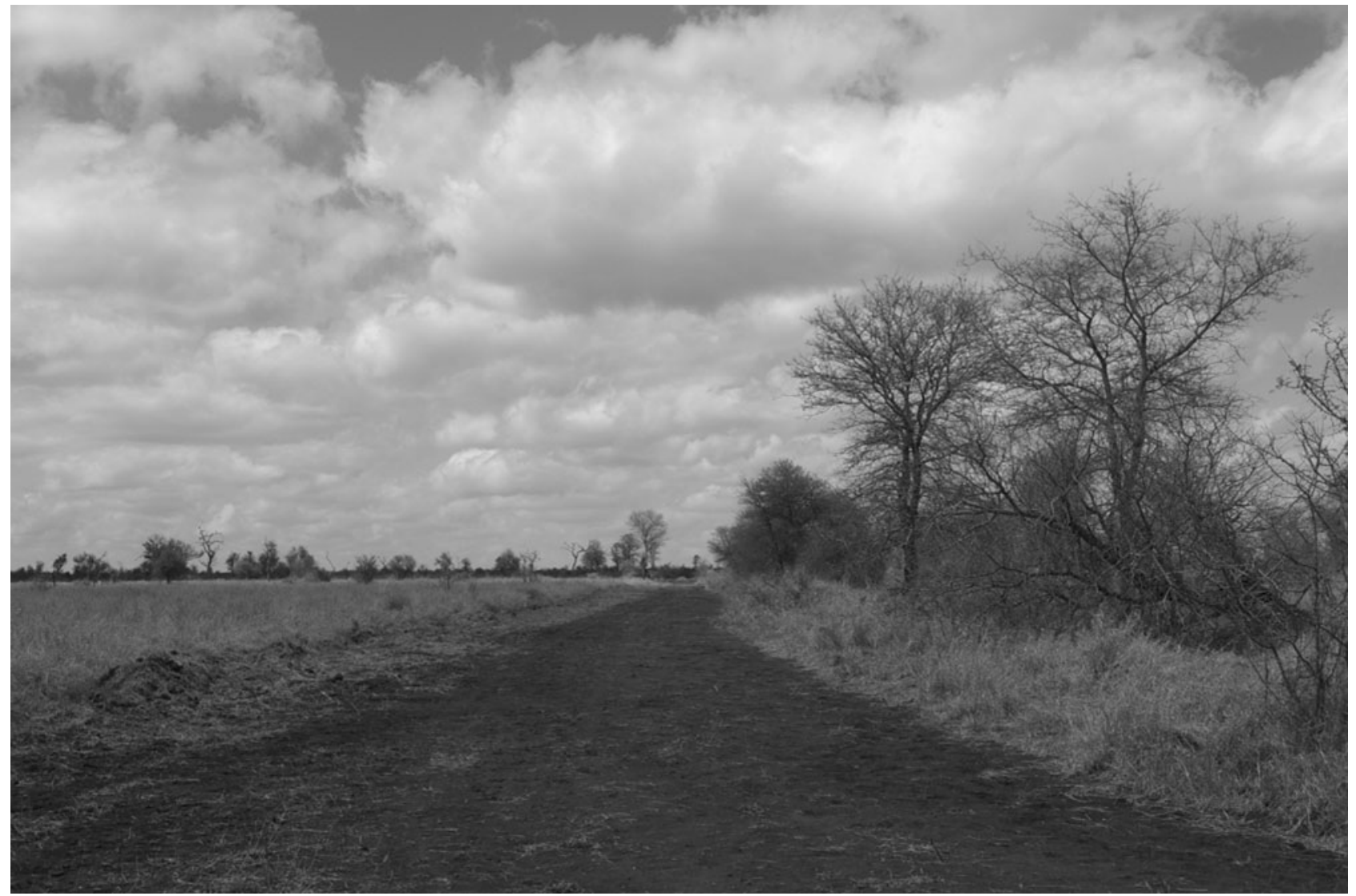

Fig. 5. Experimental burning plots in the central area of the Kruger National Park in 2006. Fire was excluded from the plot on the right for 50 years, whereas the plot on the left was subjected to fire every 2 years (Photo N. Govender).

problem. In a recent review of the implications of current ecological thinking for biodiversity conservation, Wallington et al. (2005) point to the fact that ecosystems are complex and are made up of many different species and processes that interact in different ways. Management actions that target a single species (such as elephants) or process (such as fire) alone are likely to lead to unexpected results that could cascade through the whole system, and a broader, systems approach may be required (e.g. Zavaleta et al. 2001).

\section{Effects on herbaceous plant composition}

Detailed analyses currently in progress indicate that fires in the dormant season had relatively little effect on the community composition of herbaceous plant species (M. D. Smith, unpubl. data). In contrast, fires in the wet season, and fire exclusion, resulted in changes to the herbaceous plant community composition over the duration of the experiment. For example, plots earmarked for different treatments were found to have been similar in terms of grass species richness at the start of the experiment, whereas after 50 years of treatment, plant species richness was consistently lowest on plots where fire had been excluded, or where they had been burnt in the wet growing season (February). As was the case with woody species, mean annual rainfall also influenced the results, with the effects of fire exclusion and of wet season fires being most marked on plots in areas of higher rainfall. In more arid areas, where fire treatments could not be applied as often as intended (Fig. 2), the responses of the herbaceous plants to different fire treatments were less clear, and possibly masked by the competing effects of herbivory and climatic variability.

These findings also suggest that the manipulation of fire regimes is not critical for the maintenance of herbaceous plant species diversity. Fire exclusion or extensive wet season fires, which would affect composition, are not practical options as it would not be possible to apply them consistently over large areas. The manipulation of grazing pressure (for example through the establishment or removal of artificial water sources, which have been employed extensively in the park) may be more effective ways of influencing herbaceous plant community composition (Gaylard et al. 2003).

\section{Effects on small mammals}

A study of small mammal dynamics on the experimental burning plots identified 11 species (nine rodents, one shrew and one elephant shrew). Protection from fire led to relatively high, stable small mammal density, biomass and diversity (Kern 1981). Annual fires, on the other hand, led to domination of the small mammal community by a single rodent species (Tatera leucogaster), whereas triennial burning treatments were characterised by a cycle of species determined by post-fire age. On plots burnt 
every 3 years, $T$. leucogaster dominated in the first year after fire, followed by domination by other rodent species, and finally by the shrew species Crocidura hirta in the third year after fire. Thus, whereas protection from fire seemed the best option for the conservation of small mammals, it was recognised that this would neither be possible nor desirable. Kern (1981) concluded that many small mammal species would be conserved, albeit in smaller numbers, in fire refugia across the park. This work indicated, therefore, that managers would not have to focus on the establishment of a narrow range of fire regimes to conserve small mammals.

\section{Effects on ants}

A study of the responses of ant communities to fire treatments at the Sourveld, Knobthorn-Marula and Mopane sites found no significant effect of burning on mean ant species richness and abundance between treatments, although there were significant differences in ant assemblage composition between the burnt and unburnt (control) plots (Parr et al. 2004). The study concluded that epigaeic ant assemblages appeared to be highly resistant and resilient to burning. The response of ants to fire was linked to changes in habitat cover and structure: the effect of fire on vegetation and ants was less pronounced in lower rainfall areas, where differences in vegetation structure between burnt and unburnt plots were less pronounced than in higher rainfall areas. Because of the very small effects of fire on ant communities, the study specifically recommended that conservation managers need not be concerned about the effects of fire on ant species diversity, but that they should rather 'focus concerns regarding the subtleties of fire regimes on other taxa or areas of particular concern'.

\section{Effects on birds}

Although an attempt was made to assess the effects of long-term burning treatments on bird species, the experimental burning plots proved to be too small for this purpose. The impact of fire on bird communities was therefore assessed by comparing larger areas burnt in low- and high-intensity fires with unburnt sites (Mills 2004). The study found that species richness did not differ between these treatments. Some species were less common in some treatments (for example ground-feeding and granivorous species were less common at sites that had high-intensity burns), but in none of the treatments was any species entirely absent. The study concluded that bird communities are likely to be robust to all but the most extreme fire policies, such as, for example, total fire exclusion. It was specifically noted that a 'hands-off fire policy is unlikely to affect bird communities negatively'.

\section{Effects on mycorrhizal symbiosis}

Mycorrhizal symbiosis is recognised as a key factor that could influence the response of grasses to fire and herbivory. The relationships between fire treatments, grass root architecture and mycorrhizal symbiosis were investigated on the experimental burning plots (Hartnett et al. 2004). Eighteen grass species were sampled on plots burnt every 1 and 3 years, as well as in unburnt plots. All 18 species were found to be highly colonised by arbuscular mycorrhizal fungi (AMF). Both mycorrhizal symbiosis and root system architecture were strongly affected by fire, with an increase in AMF colonisation and a decrease in root branching and fine root development with decreasing fire frequency. The fact that mycorrhizal colonisation and root system fibrousness showed opposite trends across the range of fire frequency treatments indicated that maintaining an extensive system of fine roots or an extensive network of mycorrhizal hyphae represent alternative strategies for maximising acquisition of soil resources under different fire regimes. Although Hartnett's study did not specifically address the management implications of these findings, it implies that managers need not be concerned that adherence to narrow fire regimes would have any disadvantages in terms of grass species' abilities to retain adequate levels of access to nutrients.

\section{Effects on soil}

Nitrogen is lost through volatilisation during fires, but studies on the experimental burning plots revealed that soil \% nitrogen did not decrease with increasing fire frequency, suggesting that nitrogen losses are replenished in both regularly (annually) and less regularly burnt areas (Aranibar et al. 2003). In apparent contrast to the findings regarding effects on woody shrubs in other studies, the relative abundance and nitrogen fixation of woody legumes decreased with increasing fire frequency, suggesting that woody legume nitrogen fixation is not the mechanism that balances nitrogen losses. The relatively constant $\%$ nitrogen in all fire treatments suggests the presence of other mechanisms to balance nitrogen losses by fires. A study of soil microbial communities on all burn treatments (Feig 2005) assessed overall bacterial community structure, and inferred metabolic activity through the measurement of soil respiration. It was found that there was no significant difference in soil respiration rates between fire treatments, soil types or seasons. Annual burning was also found to increase soil crusting (Mills and Fey 2004). Mills and Fey's study suggested that this may be selfperpetuating, because increased runoff is likely to increase the loss of soluble salts. However, there is no evidence, yet, that infrequent burning (every 2-6 years) may lead to severe nutrient losses and soil crusting. Frequent (annual) fires that cause crusting are unlikely on a large scale.

\section{Effects on gaseous emissions}

The SAFARI-92 initiative (Lindesay et al. 1996) made extensive use of the Kruger National Park's fire experiment to gather data on gaseous emissions, both during flaming and smouldering combustion, as well as from biogenic emissions following fires. The SAFARI work was not intended to address the aims of the experiment, but rather it made use of the infrastructure and fire management expertise available to address questions relating to the role of fire in affecting the chemistry of the atmosphere (Andreae et al. 1996; Lacaux et al. 1996; Levine et al. 1996; Parsons et al. 1996; Shea et al. 1996; Ward et al. 1996). The findings included that the magnitude of carbon and nitrogen emissions during fires is influenced by biomass, which is in turn influenced by post-fire age. Post-fire biogenic emissions of nitric oxide increased after fire, and were highest following fire on plots that had been unburnt for 35 years (this finding required that one of the control plots in the Sourveld area be burnt). The 
main focus of the SAFARI work was to provide information of relevance at a subcontinental to global scale, in terms of understanding the role that vegetation fires play in the dynamics of atmospheric chemistry. Although this work had macroscale aims from which the park's managers originally expected a low level of direct benefits, it brought home the realities of potential deposition of industrial and motor vehicle emissions and possible nitrogen leaks from upstream areas. These are important areas in which conservation authorities could easily have remained conceptually disconnected (Biggs 2003). Through having these links pointed out, managers and researchers in the park gained valuable integrative insights. These have enabled them to engage in debates on activities outside the park's boundaries that would impact on ecosystem function and conservation within the park.

\section{Overall effects of fire}

The picture that emerges from this is that fire has less effect than may have been expected. The effects of fire on the vegetation were more marked in areas that received higher rainfall, but the most notable effects are from treatments that deviate most from the existing (and for all practical purposes the achievable) fire regime. These include extremes of fire frequency (either annual burning, or total exclusion of fire), or burning in the summer wet season. None of these are practical or desirable options for fire management. Whereas fire had little effect, the total exclusion of fire had striking effects, especially in terms of increases in aboveground plant biomass, and especially in areas of higher rainfall. It is important to consider, though, that because the experiment was open to grazing and browsing, the effects of fire may have been mediated or masked; herbivory and fire are known to strongly interact in other grassland ecosystems (Collins et al. 1998).

\section{Changing paradigms in savanna fire ecology}

In addition to findings based on the fire experiment, many new insights into the role of fire in African savannas have arisen from other research. The adoption of a heterogeneity paradigm, with variability as a central concept (Mentis and Bailey 1990; Rogers 2003) has required thinking about the use of fire in ways quite different to the fixed-area, fixed-return interval approach that characterised the $1950 \mathrm{~s}$ to $1980 \mathrm{~s}$. The fact that grasses and trees coexist in savannas has been explained by disequilibrium models that invoke the irregular occurrence of fires in preventing the development of a stable state in savanna ecosystems (Scholes and Archer 1997). Higgins et al. (2000) were able to demonstrate a plausible mechanism that underlay this process - the need for variability in the intensity of successive fires. A study of the fire records for the entire Kruger National Park over more than 40 years also revealed that the area that burnt in any given year was strongly related to rainfall (and therefore grass fuels) in the preceding 2 years (van Wilgen et al. 2004); it was variability in rainfall that governed the extent of fires, and not management. Variability in fire-return periods was also strongly influenced by the sequencing of annual rainfall rather than by management. It is many of these new insights, rather than information arising from the fire experiment, that have provided the impetus for changes in management approaches in the park (see below).
How well did the treatments approximate the park's fire regimes?

The fire treatments chosen for inclusion in the fire experiment were assumed to be representative of a potential suite of regimes that could underpin management at the time that the experiment was initiated. The mean fire frequencies in the landscapes in which the experiment was established have subsequently been found to be longer (up to 7.2 years) than the 1-3-year range initially chosen for the experiment (van Wilgen et al. 2000). This was realised in 1976, when fires on 4- and 6-year cycles were added to the experiment. In reality, fire-return periods in the park are variable and skewed. For example, fires at 1- or 2-year return intervals were found to account for $65 \%$ of all area burnt per year in the Kruger National Park, but occasional longer fire-return periods (up to 30 years or more) ensured a higher mean (van Wilgen et al. 2000). Thus, although annual, biennial and triennial burn treatments are probably representative of most individual fires, they do not account for occasional longer periods between fires, which may have important ecological effects, especially in terms of the recruitment of trees into fire-resistant size classes (Higgins et al. 2000; Van Langevelde et al. 2003). The fire intensities achieved in the experimental burns were probably also not representative of the full range of actual intensities found over large areas. This is because experimental fires were mainly carried out under milder conditions for reasons of safety, resulting in fire intensities between 700 and $2800 \mathrm{~kW} \mathrm{~m}^{-1}$. Many landscape-scale fires would be of higher intensity (a small number of experimental plot fires exceeded $15000 \mathrm{~kW} \mathrm{~m}^{-1}$; Govender et al. 2006), again with significant ecological consequences for trees (Trollope et al. 1995).

\section{Fire management in the Kruger National Park}

Since the proclamation of the park, fire management has passed through several phases (van Wilgen et al. 2003). Between 1926 and 1947 , occasional but limited burning was carried out to promote grazing. Between 1948 and 1956, deliberate attempts were made to reduce the impacts of fire, by ensuring, wherever possible, that no area burnt more often than once every 5 years. From 1957 to 1980 , prescribed burning was introduced with the intention of establishing a regular, 3-year fire-return interval. The park was divided into around 400 fixed areas (called 'burning blocks'), and a program of prescribed burning intended to ensure that these blocks burnt every 3 years was initiated. This was to have continued until such time as evidence could be produced to support an alternative management approach. Between 1981 and 1991, this was changed to become more flexible. Fires were timed to take fuel loads, post-fire age and mean annual rainfall into account, with the intention of establishing more variable return intervals. Between 1992 and 2001, a 'natural' fire policy was introduced, in which lightning-ignited fires were allowed to burn freely, while at the same time attempts were made to prevent, suppress or contain all other fires. Since 2002, the park has adopted a hybrid system of patch mosaic burning (Brockett et al. 2001) and lightning fires, with tolerance of wildfires under certain conditions. Fire patterns are monitored, and tested against 'thresholds of potential concern' (van Wilgen et al. 1998; see below) within a framework of adaptive management (Biggs and Rogers 2003). 
The concept of management by 'thresholds of potential concern' was introduced in the Kruger National Park in the mid1990s (Biggs and Rogers 2003). Under this framework, upper and lower thresholds were defined for a range of ecosystem indicators. If a threshold is reached, then management interventions are considered; alternatively, the threshold could be recalibrated. In line with this policy, a range of thresholds relating to fire patterns was proposed (van Wilgen et al. 1998). The framework included thresholds relating to fire-return periods, the seasonal distribution of fires, the range of desired fire intensities, the sizeclass distribution of fires and the cause of fires (whether they were 'natural' lightning fires, or fires initiated by humans). Deviations from these thresholds were intended to alert managers to the possibility that fires were either too frequent, too infrequent, or otherwise deviating from acceptable limits in the area concerned. The way in which this influenced fire management policy is discussed further in the next section.

Recent studies (van Wilgen et al. 2004; Govender et al. 2006) investigated the impact of changing management approaches on the park's fire regimes between 1956 and 2001. They found that, at the scale of the entire park, the area that burnt in any given year was independent of the prevailing management policy; rather, it was strongly related to rainfall (and therefore grass fuels) in the preceding 2 years. Mean fire-return periods varied between 5.6 and 7.3 years under the different management policies, and variability in fire-return intervals was strongly influenced by the sequencing of annual rainfall rather than by management. These findings were surprising as they indicated that management had less influence on fire occurrence than many would have believed. On the other hand, management did affect the spatial heterogeneity of fires, their seasonal distribution, and the intensity of fires.

\section{The relative influence of fire research on fire management policies}

Scientific data and understanding do not constitute the only basis for management or policy decisions, but they can and should provide important inputs (Polikansky 1998). At the initiation of the Kruger National Park's fire experiment, it was the intention that information gathered, and periodically synthesised, would be used to improve fire management from time to time. The question can now be asked whether that was in fact the case, and also whether or not the research constitutes a valuable ongoing investment for managers. This question is best addressed by examining the rationale behind the changes in fire management approaches in the park, following the initiation of the fire experiment.

There is only one published account of the earlier management recommendations arising from the burning experiment (Anon. 1960). The report reviews preliminary experimental findings, and goes on to make several surprisingly detailed recommendations without linking them to the results of the experiment. These include the proposed exclusion of the catchment areas of rivers and wetlands from the burning program, the need for inspections of areas due to be burnt before a final decision was made to burn, the abandonment of burning in August and September and the requirement that at least 2 inches $(50 \mathrm{~mm})$ of rain should fall before any burning was initiated, and the total exclusion of areas in the north from the burning program because of their 'exceptional' plant growth. This approach essentially sought to inform management decisions by utilising expert opinion. Such expertise resided in individuals whose task it was to gain understanding from field observation and experimentation. Although the recommendations made could not have been based on the results of the fire experiment, they provide an early example of the close links that developed between researchers and managers in the park over the next few decades.

The first policy change after the initiation of the fire experiment came about in 1981. At this time, the intention to replace the more rigid attempt to apply fires on a 3-year cycle with flexible prescribed burning was made. The concerns expressed at the time are listed by van Wilgen et al. (2003), and were based on widespread observations of deteriorating grassland condition, and declining numbers of large trees. In addition, there were growing opinions that perimeter ignitions (rather than point ignitions, such as those associated with lightning-ignited fires), and a lack of variation in fire regimes, were detrimental. The degree to which the fire experiment influenced these changes is not clear, or documented, although experience gained by researchers in the application of (or inability to apply) scheduled treatments must have informed the debate to some degree.

The second major policy change in 1992 led to the introduction of a lightning-driven fire policy. The rationale for implementing this policy is summarised by Biggs and Potgieter (1999) as follows:

In 1992, forces within park management supporting notions of wilderness ecosystem management, and to an extent those striving to promote landscape patchiness, were able to obtain an overwhelming majority decision to alter the nearly 40-year run of rotational burning to an intended system of lightning-induced fires. The decision to change was taken in the face of an available alternative ... developed for the Kruger National Park in 1991.

(The alternative was based on the assessment of grass sward composition as a basis for deciding to burn or not.) As with the earlier change in 1980, information from the fire experiment apparently did not play any significant role in the decision, which hinged on ideals of wilderness management, and was influenced by developing ecological paradigms of heterogeneity.

The rationale behind the next policy change in 2001 is summarised by van Wilgen et al. (2004) as follows:

(The change) was triggered by a threshold that sought to limit human-caused fires to less than $25 \%$ of the area burnt in a given year (this threshold was included because the 'natural-fire' policy rested on promoting lightning ignitions). When the threshold was exceeded in 1996, managers first changed the target area from 25 to $50 \%$, then from an annual total to an average over 10 years. However, before the 10-year period had been reached, it became clear that it would in any case be exceeded. Most of the area that burnt in the 10 years that the lightning policy was in force burnt in fires not started by lightning (lightning fires burnt only 757660 out of 3210543 ha, or $23.6 \%$, and most fires were ignited by transborder migrants). This, coupled with growing pressure from managers who were required to contain most fires, led to the policy being changed in April 2002. 
It is clear, therefore, that this final change was also uninfluenced by results from the fire experiment.

The above assessment indicates that the fire experiment was not as important in influencing changes in policy as its originators may have intended it to be. There appear to be three important reasons for this. First, changing paradigms in ecology rendered the suite of chosen fire treatments unsuitable for addressing new questions, as they were not designed to cater for variable fire intervals and seasons on the same spot. Second, major policy changes were made in the absence any comprehensive analyses of the effects of the fire treatments; although the experiment had been maintained, it was not subjected to detailed analysis until the late 1990s (Fig. 3). Finally, changes in policy were not based on scientific evidence alone; philosophical issues were often the dominant reason for change. Other than for the addition of new treatments to the experiment (in 1976) and the subsequent policy change from fixed to flexible prescribed burning in 1981, there does not appear to be obvious correspondence between the experiment and fire management (Fig. 4).

Despite this, it should not be concluded that the experiment did not have value. It has provided experience in the application of various fire treatments over a long period and the opportunity for observation of responses, and allowed the development of understanding in a cohort of people who are now, as a result, able to debate and decide on issues relating to fire and its effects with a degree of confidence. In addition, as discussed below, the experiment will also provide a template for testing new ideas.

\section{Conclusions}

The Kruger National Park's long-term fire experiment has faced problems typical of many such experiments elsewhere. The objectives of fire management have changed over the past half a century in response to changing paradigms in savanna ecology (from 'balance of nature' to 'flux of nature' concepts) and a new focus on the broader conservation of biodiversity (as opposed to the conservation of large game animals; Bond and Archibald 2003). The experiment was therefore not ideally equipped to deal with new questions, or to address the full suite of 'thresholds of potential concern' relating to fire patterns that were developed in the 1990s to guide the park's fire management (van Wilgen et al. 1998). For these and other reasons, the experiment has been criticised, and has been under threat of closure. For a long period, the experiment produced very few tangible products (Fig. 3), and as a result was not highly visible - this would have caused an unintended increase in its vulnerability.

The fact that the Kruger National Park's fire experiment has been, and still is, maintained is remarkable, given that it has not played an obviously dominant role in informing major management decisions - the principal reason for its establishment. Its continued existence today is probably the result of a combination of factors. These include its dedicated maintenance by a small number of people, as well as a widely held belief among managers that basic research will influence the understanding of fundamental ecosystem function, and hence ultimately promote appropriate management (Biggs 2004). There is recognition, embedded in the park's culture and based on a history of science-based management, that basic research is necessary to make good decisions about how to manage ecosystems.
This has led to an ongoing support of research, including support for the fire experiment, even if the results did not have obvious immediate application. Today, given the growing importance of adaptive management (Biggs and Rogers 2003), the fire experiment forms an important component of the integrated approach that incorporates inventory and monitoring, research, and adaptive management (Wallington et al. 2005).

The experiment has also delivered some benefits that were unforeseen at the time of establishment. The baseline surveys conducted at the start of the experiment provide a sample of the vegetation condition in the park in the 1950s, and are the only existing, detailed information on the state of the vegetation at the time. As such, they are a valuable resource in their own right, and have recently provided the only data against which the impact of growing numbers of elephants can be assessed. The management of the park's burgeoning elephant population, and the effects of such management on vegetation, have developed into a major issue (Whyte et al. 2003; Owen-Smith et al. 2006). Having a benchmark against which these impacts can be assessed is extremely valuable, and would not have existed if it were not for the fire experiment's baseline surveys. The use of the experiment to address new and unforeseen questions (such as the role of vegetation fires in the dynamics of the atmosphere; Lindesay et al. 1996) provides further confirmation of its value, as does its use in the interpretation of satellite images (Heatherington 1997; Landmann 2003) and for the development of conceptual ecological models (Higgins et al. 2000; Van Langevelde et al. 2003). Currently, and in the light of these considerations, the experiment is viewed as a comprehensive scientific outdoor laboratory to be utilised to promote the understanding of fire-herbivory interactions and the effects of different combinations of fire frequency and season on the ecosystem. The experiment will in all likelihood also become part of the South African Earth Observation Network (SAEON; Van Jaarsveld and Biggs 2000). The SAEON network aims to provide long-term reliable data for scientific research and for informing decision-making for a knowledge society and an improved quality of life.

Seen from an ecological perspective, the experiment remains extremely valuable, and provides useful opportunities for the testing of ideas, by virtue of having been subjected to rigorous, repeated, and documented fire treatments over many decades. Such sites are very difficult to find, and the experiment has already been fruitfully used to test emerging ideas in ecology and global change. Indications are that this role is set to grow in importance. The fire experiment has recently provided the basis for examining new research questions, with a view to developing an improved conceptual and predictive understanding of savanna ecology. This will be attempted through the additional experimental manipulation of the vegetation under different fire treatments. The additional treatments include, for example, the complete fencing of some plots, and the erection of smaller exclosures, and irrigation and shelter from rainfall on others. These experiments have already been initiated utilising research funding from donor foundations, and are aimed at examining the combined effects of fire, herbivory, and rainfall on the dynamics of the vegetation. The effects of fire may not manifest themselves over the short time periods covered by most experiments, and this experiment provides an ideal template for examining the longterm consequences of ecosystem manipulation. In addition, the 
existence of this established, long-term experiment located in an area that still supports the full complement and diversity of large mammalian herbivores under whose influence the vegetation evolved make it a unique asset.

Finally, the experiment also provides the opportunity to physically demonstrate the consequences of the application or exclusion of fire over many decades to a range of stakeholders, from policymakers to ecosystem managers and students. With regard to the last group, the experiment is regularly used as part of the field curricula of local and international students of ecology, and as a basis for research by masters and doctoral students. We conclude, therefore, that the experiment is and will remain extremely valuable.

\section{Acknowledgements}

We thank South African National Parks for access to data and information, and Mendy Smith for valuable comments on the manuscript. The team that maintained the experiment for many decades, especially Andre Potgieter, deserve special mention. We also acknowledge the significant contribution of Winston Trollope in rekindling and developing the science behind the experiment in the 1980 s.

\section{References}

Andersen AN, Cook GD, Williams RJ (2003) 'Fire in Tropical Savannas: the Kapalga Experiment.' (Springer Verlag: New York)

Andreae MO, Atlas E, Harris GW, Helas G, de Kock A, Koppmann R, Maenhaut W, Manø S, Pollock J, Rudolf D, Scharffe D, Schebeske G, Welling M (1996) Methyl halide emissions from savanna fires in southern Africa. Journal of Geophysical Research 101, 23603-23614. doi:10.1029/95JD01733

Anon. (1960) Annual report of the Biologist, Kruger National Park. Koedoe 3, 173-195

Aranibar JN, Macko SA, Anderson IC, Potgieter ALF, Sowry R, Schugart HH (2003) Nutrient cycling responses to fire frequency in the Kruger National Park (South Africa) as indicated by stable isotope analysis. Isotopes Environment Health Studies 39, 141-158. doi:10.1080/ 1025601031000096736

Biggs HC (2003) Integration of science: success, challenges, and the future. In 'The Kruger Experience: Ecology and Management of Savanna Heterogeneity'. (Eds J du Toit, KH Rogers, HC Biggs) pp. 468. (Island Press: New York)

Biggs HC (2004) Promoting ecological research in national parks - a South African perspective. Ecological Applications 14, 21-24. doi:10.1890/ 03-5105

Biggs HC, Potgieter ALF (1999) Overview of the fire management policy of the Kruger National Park. Koedoe 42, 101-110.

Biggs HC, Rogers KH (2003) An adaptive system to link science, monitoring, and management in practice. In 'The Kruger Experience: Ecology and Management of Savanna Heterogeneity'. (Eds J du Toit, KH Rogers, HC Biggs) pp. 59-80. (Island Press: New York)

Biggs R, Biggs HC, Dunne TT, Govender N, Potgieter ALF (2003) Experimental burn plot trial in the Kruger National Park: history, experimental design and suggestions for data analysis. Koedoe 46, 1-15.

Bond WJ, Archibald S (2003) Confronting complexity: fire policy choices in South African savanna parks. International Journal of Wildland Fire 12, 381-389. doi:10.1071/WF03024

Bond WJ, Keeley JE (2005) Fire as a global 'herbivore': the ecology and evolution of flammable ecosystems. Trends in Ecology \& Evolution 20 , 387-394. doi:10.1016/J.TREE.2005.04.025

Brockett BH, Biggs HC, van Wilgen BW (2001) A patch mosaic burning system for conservation areas in southern Africa. International Journal of Wildland Fire 10, 169-183. doi:10.1071/WF01024
Collins SL, Knapp AK, Briggs JM, Blair JM, Steinauer EM (1998) Modulation of diversity by grazing and mowing in native tallgrass prairie. Science 280, 745-747. doi:10.1126/SCIENCE.280.5364.745

Davidson RL, Brynard AM, Gillard P, LeCastas G, Leigh J (1961) Veld burning: a calibration of the belt transect method in Combretum woodland in the Kruger National Park. Koedoe 4, 31-41.

Eckhardt HC, van Wilgen BW, Biggs HC (2000) Trends in woody vegetation cover in the Kruger National Park, South Africa, between 1940 and 1998. African Journal of Ecology 38, 108-115. doi:10.1046/J.13652028.2000.00217.X

Enslin BW, Potgieter ALF, Biggs HC, Biggs R (2000) Long term effects of fire frequency and season on the woody vegetation dynamics of the Sclerocarya birrea/Acacia nigrescens savanna of the Kruger National Park. Koedoe 43, 27-37.

Freitag S (1998) The Kruger National Park and the analysis of historic data sets: where are we going? South African Journal of Science 94, 146.

Feig GT (2005) The effect of fire regime on soil microbial community composition and activity. MSc Thesis, University of the Witwatersrand, Johannesburg.

Fuhlendorf SD, Engle DM (2001) Restoring heterogeneity on rangelands: ecosystem management based on evolutionary grazing patterns. Bioscience 51, 625-632. doi:10.1641/0006-3568(2001)051[0625 RHOREM]2.0.CO;2

Fuhlendorf SD, Engle DM (2004) Application of the fire-grazing interaction to restore a shifting mosaic on tallgrass prairie. Journal of Applied Ecology 41, 604-614. doi:10.1111/J.0021-8901.2004.00937.X

Gaylard A, Owen-Smith N, Redfern J (2003) Surface water availability: implications for heterogeneity and ecosystem processes. In 'The Kruger Experience: Ecology and Management of Savanna Heterogeneity'. (Eds J du Toit, KH Rogers, HC Biggs) pp. 171-188. (Island Press: New York)

Gertenbach WPD, Potgieter ALF (1979) Veldbrandnavorsing in die struikmopanieveld van die Nasionale Krugerwildtuin. Koedoe 22, 1-28.

Govender N, Trollope WSW, van Wilgen BW (2006) The effect of fire season, fire frequency, rainfall and management on fire intensities in savanna vegetation in South Africa. Journal of Applied Ecology 43, 748-758. doi:10.1111/J.1365-2664.2006.01184.X

Hartnett DC, Potgieter ALF, Wilson GWT (2004) Fire effects on mycorrhizal symbiosis and root systems architecture in southern African savanna grasses. African Journal of Ecology 42, 328-337. doi:10.1111/J.13652028.2004.00533.X

Hetherington DS (1997) GIS and satellite RS as tools to assist fire management protocols in the national parks of southern Africa. MSc Thesis, University of Greenwich.

Higgins SI, Bond WJ, Trollope WSW (2000) Fire, resprouting and variability: a recipe for grass-tree coexistence in savanna. Journal of Ecology 88, 213-229. doi:10.1046/J.1365-2745.2000.00435.X

Higgins SI, Bond WJ, February EC, Bronn A, Euston-Brown DIW, Enslin B, Govender N, Rademan L, O'Regan S, Potgieter ALF, Scheiter S, Sowry R, Trollope L, Trollope WSW (2007) Effects of four decades of fire manipulation on woody vegetation structure in savanna. Ecology 88, 1119-1125. doi:10.1890/06-1664

Jacobs OS, Biggs R (2001) The effect of different fire treatments on the population structure of the marula Sclerocarya birrea (A. Rich.) subsp. caffra (Sond.) (Kokwaro and Gillet 1980) in the Kruger National Park. African Journal of Range and Forage Science 18, 13-24

Jones CL, Smithers NL, Scholes MC, Scholes RJ (1990) The effect of fire frequency on the organic components of a basaltic soil in the Kruge National Park. South African Journal of Plant and Soil 7, 236-238.

Kennedy AD, Potgieter ALF (2003) Fire season affects size and architecture of Colophospermum mopane in southern African savannas. Plant Ecology 167, 179-192. doi:10.1023/A:1023964815201

Kern NG (1977) The influence of fire on populations of small mammals of the Kruger National Park. MSc Thesis, University of Pretoria.

Kern NG (1981) The influence of fire on populations of small mammals of the Kruger National Park. Koedoe 24, 125-158. 
Knapp AK, Briggs JM, Hartnett DC, Collins SL (1998) 'Grassland Dynamics: Long-term Ecological Research in Tallgrass Prairie.' (Oxford University Press: New York)

Lacaux JP, Delmas R, Jambert C, Kuhlbush TAJ (1996) $\mathrm{NO}_{\mathrm{x}}$ emissions from African savanna fires. Journal of Geophysical Research 101, 2358523596. doi:10.1029/96JD01624

Landmann T (2003) Characterizing sub-pixel Landsat ETM+ fire severity on experimental fires in the Kruger National Park, South Africa. South African Journal of Science 99, 357-360.

Levine JS, Winstead EL, Parsons DAB, Scholes MC, Scholes RJ, Cofer WR, Cahoon DR, Sebacher DI (1996) Biogenic soil emissions of nitric oxide (NO) and nitrous oxide $\left(\mathrm{N}_{2} \mathrm{O}\right)$ from savannas in South Africa: the impact of wetting and burning. Journal of Geophysical Research 101, 23689-23698. doi:10.1029/96JD01661

Lindesay JA, Andreae MO, Goldammer JG, Harris G, Annegarn HJ, Garstang M, Scholes RJ, van Wilgen BW (1996) International Geosphere-Biosphere Programme/International Global Atmospheric Chemistry SAFARI-92 field experiment: background and overview. Journal of Geophysical Research 101, 23521-23530. doi:10.1029/ 96JD01512

Mentis MT, Bailey AW (1990) Changing perceptions of fire management in savanna parks. Journal of the Grassland Society of Southern Africa 7, $81-85$

Mills AJ, Fey MV (2004) Frequent fires intensify soil crusting: physicochemical feedback in the pedoderm of long-term burn experiments in South Africa. Geoderma 121, 45-64. doi:10.1016/ J.GEODERMA.2003.10.004

Mills MSL (2004) Bird community responses to savanna fires: should managers be concerned? South African Journal of Wildlife Research 34, 1-11.

O'Regan SP (2005) Responses of the woody vegetation in the Pretoriuskop sourveld savannas of the Kruger National Park to fires burnt at different frequencies. MSc Thesis, University of the Witwatersrand, Johannesburg.

Otter LB (1992) Soil carbon fractionation of sand and clay soils under different burning regimes. BSc (Honours) Thesis, University of the Witwatersrand, Johannesburg.

Owen-Smith N, Kerley GIH, Page B, Slowtow R, van Aarde RJ (2006) A scientific perspective on the management of elephants in the Kruger National Park and elsewhere. South African Journal of Science 102, 389-394.

Parr CL, Robertson HG, Biggs HC, Chown SL (2004) Response of African savanna ants to long-term fire regimes. Journal of Applied Ecology 41, 630-642. doi:10.1111/J.0021-8901.2004.00920.X

Parsons DAB, Scholes MC, Scholes RJ, Levine JS (1996) Biogenic NO emissions from savanna soils as a function of fire regime, soil type, soil nitrogen and water status. Journal of Geophysical Research 101, 23683-23688. doi:10.1029/95JD02140

Polikansky D (1998) Science and decision-making for water resources. Ecological Applications 8, 610-618. doi:10.1890/1051-0761(1998)008 [0610:SADMFW]2.0.CO;2

Rogers KH (2003) Adopting a heterogeneity paradigm: implications for management of protected savannas. In 'The Kruger Experience: Ecology and Management of Savanna Heterogeneity'. (Eds J du Toit, KH Rogers, HC Biggs) pp. 468. (Island Press: New York)

Scholes RJ, Archer SR (1997) Tree-grass interactions in savannas. Annual Review of Ecology and Systematics 28, 517-544. doi:10.1146/ ANNUREV.ECOLSYS.28.1.517

Shackleton CM, Scholes RJ (2000) Impact of fire frequency on woody community structure and soil nutrients in the Kruger National Park. Koedoe 43, 75-81.

Shea RW, Shea BW, Kauffman JB, Ward DE, Haskins CI, Scholes MC (1996) Fuel biomass and combustion factors associated with fires in savanna ecosystems of South Africa and Zambia. Journal of Geophysical Research 101, 23551-23568. doi:10.1029/95JD02047
Trollope WSW, Potgieter ALF (1985) Fire behaviour in the Kruger National Park. Journal of the Grassland Society of Southern Africa 2, 17-22.

Trollope WSW, Potgieter ALF, Zambatis N (1989) Assessing veld condition in the Kruger National Park using key grass species. Koedoe 32, 67-93.

Trollope WSW, Potgieter ALF, Zambatis N (1995) Effect of fire intensity on the mortality and topkill of bush in the Kruger National Park in South Africa. Bulletin of the Grassland Society of Southern Africa 6, 66.

Trollope WSW, Trollope LA, Potgieter ALF, Zambatis N (1996) SAFARI-92 characterization of biomass and fire behaviour in the small experimental burns in the Kruger National Park. Journal of Geophysical Research 101, 23531-23541. doi:10.1029/96JD00691

Trollope WSW, Potgieter ALF, Biggs HC, Trollope LA (1998) Report on the experimental burning plots (EBP) trial in the major vegetation types of the Kruger National Park. Kruger National Park Scientific Services Report 9/98. (Skukuza, Mpumalanga, South Africa)

Van der Schijff HP (1958) Inleidende verslag oor veldbrandnavorsing in die Nasionale Krugerwildtuin. Koedoe 1, 60-93.

Van Jaarsveld AJ, Biggs HC (2000) Broad participation enhances initial steps toward a South African ecosystem observatory system (LTER). South African Journal of Science 96, 63-66.

Van Langevelde F, van de Vijver CADM, Kumar L, van de Koppel J, De Ridder N, van Andel J, Skidmore AK, Hearne JW, Stroosnijder L, Bond WJ, Prins HHT, Rietkerk M (2003) Effects of fire and herbivory on the stability of savanna ecosystems. Ecology 84, 337-350. doi:10.1890/0012-9658(2003)084[0337:EOFAHO]2.0.CO;2

van Wilgen BW, Biggs HC, Potgieter ALF (1998) Fire management and research in the Kruger National Park, with suggestions on the detection of thresholds of potential concern. Koedoe 41, 69-87.

van Wilgen BW, Biggs HC, O'Regan S, Mare N (2000) A fire history of the savanna ecosystems in the Kruger National Park, South Africa, between 1941 and 1996. South African Journal of Science 96, 167-178.

van Wilgen BW, Trollope WSW, Biggs HC, Potgieter ALF, Brockett BH (2003) Fire as a driver of ecosystem variability. In 'The Kruger Experience: Ecology and Management of Savanna Heterogeneity'. (Eds J du Toit, KH Rogers, HC Biggs) pp. 149-170. (Island Press: New York)

van Wilgen BW, Govender N, Biggs HC, Ntsala D, Funda XN (2004) Response of savanna fire regimes to changing fire management policies in a large African national park. Conservation Biology 18, 1533-1540. doi:10.1111/J.1523-1739.2004.00362.X

van Wyk P (1971) Veld burning in the Kruger National Park: an interim report of some aspects of research. In 'Proceedings Annual Tall Timbers Fire Ecology Conference: Number 11. Fire in Africa', 22-23 April 1971. (Ed. EV Komarek) pp. 9-32. (Tall Timbers Research Station: Tallahassee, FL)

Wallington TJ, Hobbs RJ, Moore SA (2005) Implications of current ecological thinking for biodiversity conservation: a review of the salient issues. Ecology and Society 10, 15. Available at http://www.ecologyandsociety. org/vol10/iss1/art15/ [Verified 25 September 2007]

Ward DE, Hao WM, Susott RA, Babbitt RE, Shea RW, Kauffman JB, Justice CO (1996) Effect of fuel consumption efficiency and emission factors for African savanna ecosystems. Journal of Geophysical Research 101, 23569-23576. doi:10.1029/95JD02595

Webber NW (1979) The effects of fire on soil/plant ecological relationships in the southern part of the Kruger National Park: a study on soil geography. MSc Thesis, University of South Africa, Pretoria.

Whyte IJ, van Aarde RJ, Pimm SL (2003) Kruger's elephant population: its size and consequences for ecosystem heterogeneity. In 'The Kruger Experience: Ecology and Management of Savanna Heterogeneity'. (Eds J du Toit, KH Rogers, HC Biggs) pp. 332-348. (Island Press: New York)

Zavaleta ES, Hobbs RJ, Mooney HA (2001) Viewing invasive species removal in a whole-ecosystem context. Trends in Ecology \& Evolution 16, 454-459. doi:10.1016/S0169-5347(01)02194-2

Manuscript received 12 August 2006, accepted 23 July 2007 